\title{
Inclusão social via acessibilidade digital: Proposta de inclusão digital para Pessoas com Necessidades Especiais ${ }^{1}$
}

\author{
Prof. Dra. Liliana Maria Passerino² \\ UFRGS \\ liliana@cinted.ufrgs.br \\ Prof. Dra. Sandra Portella Montardo3 \\ FEEVALE \\ sandramontardo@feevale.br
}

\begin{abstract}
Resumo: Este artigo discute, define e relaciona os conceitos de inclusão social e inclusão digital entre si. Posteriormente, propõe um novo viés de análise e concepção da inclusão digital por meio da aplicação dos princípios de acessibilidade digital na web, em geral, e nas ferramentas da Web 2.o. Esta proposição se apóia na constatação de que a socialização colabora para o desenvolvimento de Pessoas com Necessidades Especiais (PNE). É nesse contexto que a acessibilidade digital aplicada às ferramentas de socialização on-line figura como medida de inclusão digital. Dessa forma, pretende-se elaborar um conceito de inclusão digital que contemple os diferentes setores sociais imbricados no mesmo, além de debater as possibilidades de inclusão digital partindo do conceito de acessibilidade digital.
\end{abstract}

Palavras-Chave: Inclusão Digital, Acessibilidade Digital, Inclusão Social, Pessoas com Necessidades Especiais (PNE), Tecnologias de Informação e de Comunicação (TIC).

\footnotetext{
${ }^{1}$ Trabalho apresentado ao Grupo de Trabalho "Tecnologias de Informação e de Comunicação", do XI Colóquio Internacional sobre a Escola Latino Americana de Comunicação, na Universidade Católica de Pelotas, em Pelotas, RS, de 7 a 9 de maio de 2007. 2 Doutora em Informática na Educação, pela Universidade Federal do Rio Grande do Sul. Pesquisadora em Informática na Educação Especial e professora da Faculdade de Educação, Departamento de Estudos Especializados, UFRGS.

3 Doutora em Comunicação Social pelo PPGCOM-PUCRS, Linha de Pesquisa Tecnologias do Imaginário. Fez Estágio de Doutorado na Université René Descartes, Paris V, Sorbonne. Professora do Curso de Comunicação Social do Centro Universitário Feevale e pesquisadora do Grupo de Pesquisa Comunicação e Cultura na mesma instituição.
} 


\begin{abstract}
This paper aims to discuss and define the concepts of social inclusion and digital inclusion. Furthermore, it has the goal of relating both ideas. Subsequently, it proposes a new perspective of analysis and comprehension of digital inclusion through the application of the principles of digital accessibility on the web, in general, and on the tools of the web 2.o. This proposition has as a support the realization that socialization contributes to the development of the disabled. In this context, digital accessibility applied to on-line socialization tools figures as a step of digital inclusion. Thus, this article intends to develop a concept of digital inclusion that contemplates the different social sectors that overlap each other on it. In addition to this, it aims to debate the possibilities of digital inclusion, starting from the concept of digital accessibility.
\end{abstract}

Key words: digital inclusion, digital accessibility, social inclusion, the disabled, technologies of information and communication.

Resumen: Este paper discute, define y relaciona entre si los conceptos de inclusion social e inclusión digital. Propondo una nueva perspectiva de análisis para la inclusion digital a partir de la aplicacion de principios de accesibilidad digital en la Web, en general y en las herramientas Web 2.O en especial, Esta propuesta apoyase, justamente, en la constatación que la socializacion colabora y contribuye para el desarrollo de personas con necesidades especiales (PNE). Es, por lo tanto, en este contexto que la accesibilidad digital aplicada a las herramientas de socializacion on-line consta como parámetro de inclusión digital. De esta manera pretendese elaborar un concepto de inclusión digital que contemple los diferentes sectores sociales participantes del mismo, además de debater las posibilidades de inclusion digital a partir del concepto de accesibilidad digital.

Palavras-Clave: Inclusión Digital, Accesibilidad Digital, Inclusión Social, Personas com Necesidades Especiales (PNE), Tecnologias de Información y Comunicación.

Resumé: Cet article discute, définit et met en rapport les concepts d'inclusion social et d'inclusion numérique. Après, il propose un nouveau biais d'analyse et de conception de l'inclusion numérique à travers l'application des principes d accessibilité numérique dans la web, en générale, et dans les outils de la Web 2.o. Cette proposition part de la constatation selon laquelle la socialisation collabore au dévellopement des handicapés. C`est dans ce contexte que l'accessibilité numérique appliquée aux outils de socialisation en-ligne figure comme mésure d inclusion numérique. Ainsi, on veut élaborer un concept d'inclusion numérique qui contemple les differents secteurs sociaux imbriqués et provoque le débat sur possibilités d inclusion numérique concernant le concept d'accessibilité numérique.

Mot-Clés: Inclusion Numérique, Accessibilité Numérique, Inclusion Social, Handicapé, Technologies de Information et de Communication (TIC). 


\section{Introdução}

A inclusão enquanto processo social tem ganhado destaque no Brasil e no mundo nas últimas duas décadas. Porém, muito dos debates, longe de esclarecer e aprimorar conceitos construindo um arcabouço teórico consistente, tem ajudado a "incluir" na questão uma série de aspectos que pouco tem contribuído para o avanço científico. Como resultado desse fenômeno que considera tudo um "processo de inclusão", encontra-se setores da sociedade repetindo ações antigas "travestidas" de "ações de inclusão".

Em busca do estabelecimento de relação entre inclusão social e digital através do conceito de acessibilidade digital, o texto está organizado em seções seguintes que abordam os seguintes temas: inclusão social, inclusão digital, inclusão digital de Pessoas com Necessidades Especiais (PNE) e acessibilidade digital.

\section{Inclusão social: um conceito por construir}

Nos documentos oficiais (Decreto $\mathrm{N}^{\circ}$ 914/93; Lei 7853/89; Programa PROJOVEM, entre outros), o conceito de inclusão compreende, segundo Oliveira (2004), um convidar a que se aproximem aqueles que estiveram historicamente excluídos ou deixado de lado. Tal conceituação, embora "bem intencionada", deixa espaços para fragilidades. Uma das principais fragilidades centra-se na questão da autoridade para convidar os excluídos a se aproximarem. Concordando com este questionamento enfatizado por Oliveira (2004), levanta-se outros considerados ainda mais importantes: a inclusão proposta nos documentos oficiais parte de um "convite" e não de uma verdadeira intenção de inclusão. Um convite que requer a movimentação dos excluídos, mas parece não exigir a contrapartida dos já incluídos para se adaptar ou criar as condições necessárias para que esses historicamente excluídos não voltem a essa situação.

Outro problema presente na definição proposta é que considera o universo de forma dualista, como se alguém pudesse ser considerado incluído ou excluído totalmente, isto é, de todos os setores e espaços da sociedade. Situação esta impossível e que será discutida mais adiante. 
Alguns autores tentam definir inclusão a partir da definição de exclusão. Segundo Sposati (1996), inclusão e exclusão são processos sociais interdependentes vinculados principalmente à distribuição de renda e oportunidades. Nesse sentido, Azevedo e Barros (2004) consideram a inclusão como o movimento permanente na busca de igualdade de condições e oportunidades para evitar diversas situações de privação. Esta definição pode ser considerada um tanto limitada, pois a inclusão não pode ser pensada em apenas um dos aspectos sociais. Os autores citados definem inclusão a partir da exclusão, sendo a mesma

De acordo com Dupas (2000), a exclusão social é um fenômeno multidimensional que extrapola a dimensão de pobreza. Embora ela seja uma dimensão fundamental na constituição do fenômeno, o mesmo conta também com outras dimensões como educação, saúde, lazer, religião, cultura, etnia, política, economia, entre outras.

Numa posição claramente contrária ao "dualismo" que os diversos autores analisados estabelecem, propõe-se que inclusão não pode ser analisada a partir do conceito de exclusão e que este binômio não pode ser considerado como constituído por "lados opostos" e excludentes, pois as pessoas podem estar excluídas de algum processo porém incluídas na sociedade, não se tratando de uma forma de ser, e sim de uma situação dentro de um contexto determinado.

Nesse sentido, Ladeira e Amaral (1999) propõem uma definição mais coerente, conceituando-a como um processo que se prolonga ao longo da vida de um indivíduo e que tem por finalidade a melhoria da qualidade de vida do mesmo. Podese concordar com esta definição que desloca o foco da questão inclusão X exclusão como fenômeno determinístico e o situa como um processo longo e vinculado à qualidade de vida. Porém, opta-se por discordar parcialmente dos autores que centram a inclusão no indivíduo e não no contexto sócio-histórico e cultural no qual o indivíduo se constitui. Desta forma, não se pretende falar de indivíduos incluídos ou excluídos, e sim de grupos em contextos sociais que participam do fenômeno da inclusão como processo social em busca de melhoria na qualidade de vida dos membros do grupo. Assim, para Sposati (1996) a inclusão concentra-se na busca pelo acesso a quatro utopias básicas: autonomia de renda (capacidade do indivíduo de suprir suas necessidades vitais, culturais e sociais), desenvolvimento humano 
(condição dos indivíduos em sociedade desenvolverem suas capacidades intelectuais e biológicas de forma a atingir o maior grau de capacidade humana possível), equidade (garantia de igualdade de direitos e oportunidades respeitando a diversidade humana) e qualidade de vida (a democratização dos acessos às condições de preservação do homem, da natureza e do meio ambiente e a redução da degradação ambiental). Para tanto, de acordo com Azevedo e Barros (2004), é necessário uma redistribuição da riqueza social e tecnológica para os cidadãos o que nos leva ao conceito de Inclusão Digital ser abordado no próximo tópico.

Para finalizar este item gostaríamos de destacar uma definição de inclusão construída a partir das diversas tendências e discussões apresentadas e que busca, de certa forma, mostrar o caráter multidimensional do conceito.

Considera-se inclusão, portanto, o processo estabelecido dentro de uma sociedade mais ampla que busca satisfazer necessidades relacionadas com qualidade de vida, desenvolvimento humano, autonomia de renda e equidade de oportunidades e direitos para os indivíduos e grupos sociais que em alguma etapa da sua vida encontram-se em situação de desvantagem com relação a outros membros da sociedade.

Este processo eminentemente social perpassa por todas as dimensões da vida em sociedade e é permanente, embora não constante, na vida dos sujeitos, sendo que estes indivíduos ocupam posições ${ }^{4}$ diferenciadas de incluídos ou excluídos que podem ser concomitantes e muitas vezes não excludentes ao longo da suas vidas. No próximo item, busca-se relacionar este ponto de vista no âmbito da inclusão digital.

\section{Inclusão digital}

Da mesma forma que inclusão social, o termo inclusão digital é empregado em diferentes contextos, sendo raro que alguém defina o conceito em sua positividade. Por outras palavras, fala-se de exclusão digital em termos da falta de recursos computacionais e de rede e da debilidade de acesso e de produção de informação em função disso. 
Como uma exceção, Sampaio, explicitamente, propõe que inclusão digital "é o direito de acesso ao mundo digital para o desenvolvimento intelectual (educação, geração de conhecimento, participação e criação) e para o desenvolvimento de capacidade técnica e operacional" (Sampaio apud SPIGAROLI; SANTOS; SCHLÜNZEN; et al., 2005, pp. 213-214). Ou seja, mais do simplesmente ter acesso a computadores em rede, é preciso ter capacidade de operá-los com autonomia.

Em Tecnologia e Inclusão Social. A exclusão digital em debate (2006) ${ }^{5}$, de Mark Warschauer, constata-se uma abordagem ampla e suficiente do tema. Ao analisar a relação entre tecnologia de informação e comunicação (TIC) e a inclusão social, Warschauer (2006) problematiza a causalidade existente entre acesso a computadores/web e inclusão digital a partir de uma pesquisa empírica realizada em países de quatro continentes ${ }^{6}$, inclusive no Brasil.

Ao constatar que projetos que forneciam hardware e software e prestavam pouca atenção aos sistemas social e humano não surtiam resultados satisfatórios quanto à inclusão digital, o autor (2006) propõe que estes sistemas deveriam mudar para que a tecnologia fizesse a diferença. Para que isso aconteça, as TIC não devem ser uma variável exterior ao processo de inclusão, mas devem estar entrelaçadas nos sistemas e nos processos sociais das comunidades a serem contempladas por um projeto dessa natureza. Nesse sentido, promover a inclusão social significa "focalizar na transformação e não na tecnologia” (Jarboe apud WARSCHAUER, 2006, p. 24).

Além disso, Warschauer (2006) complementa que a ilusão de superação da exclusão digital está alicerçada na falsa idéia de uma divisão binária entre ter acesso à informação digital e não ter acesso à informação digital. Cisler (apud Warschauer, 2006, p. 22), propõe que existem gradações quanto o acesso a TIC. Assim, os projetos de inclusão digital devem focar a promoção do processo de inclusão social e não a superação da exclusão digital.

Estar incluído socialmente pressupõe verificar o que significa estar incluído em cada época, noção intrinsecamente ligada ao surgimento e alcance dos meios de comunicação na sociedade na visão do Warschauer (2006). Com isso, o autor (2006) parte da premissa de que "a capacidade de acessar, adaptar e criar novo

5 Tradução de Technology and Social Inclusion: Rethinking the Digital Divide (2003).

${ }^{6}$ China, India, Brasil, Irlanda,Califórnia, Havaí e Egito. 
conhecimento por meio do uso das novas TIC é decisiva para a inclusão social na época atual" (WARSCHAUER, 2006, p. 25).

Frente a isso, o autor (2006) sistematiza que recursos físicos (computadores e conectividade), recursos digitais (material digital disponível on-line em termos de conteúdo e linguagem), recursos humanos (letramento e educação para utilização da informática e da comunicação on-line) e recursos sociais (estrutura comunitária, institucional e da sociedade que apóiam o acesso às TIC), ao serem empregados como contribuintes ao acesso às TIC para acessar, adaptar e criar conhecimento, vão favorecer um círculo virtuoso para ampliar e fomentar novos recursos neste sentido.

Por fim, Warschauer (2006) complementa que projetos de inclusão que se valham das TIC devem estar abertos à inovação e à flexibilidade para que sejam proveitosamente aplicados a realidades locais, satisfazendo assim necessidades da economia e da sociedade da informação em mudança acelerada. Na medida em que se centra nas práticas sociais de determinado grupo, uma iniciativa de inclusão social via TIC vai não só proporcionar o uso deste tipo de tecnologia, mas também favorecer sua geração e aperfeiçoamento.

Vale relacionar esta perspectiva de inclusão digital com a noção de inclusão social proposta anteriormente, na medida em que também se prevê aqui uma ação permanente e progressiva de inclusão social, não limitando esta questão à instalação de máquinas ou ao fornecimento de softwares, mas à implantação e renovação de processos inclusivos a partir da autonomia dos usuários.

No Brasil, uma primeira iniciativa de sua inscrição em um mundo informatizado foi o Programa Sociedade da Informação (Decreto 3.294) em 1999. No ano seguinte, o governo brasileiro lançou o Livro Verde (Takashi, 2000) como resultado parcial dos dados obtidos daquele projeto, com o que se obteve um mapa do acesso aos computadores e à Internet no país.

Em nível nacional, o Comitê Gestor de Internet (CGI) desenvolve políticas públicas e, através de parcerias com IBGE e Ibope, aplica pesquisas embasadas em indicadores que possibilitam a comparabilidade internacional quanto às TIC no Brasil. No entanto, em função desse alinhamento com entidades internacionais no 
que se refere a indicadores quanto à posse e uso de $\mathrm{TIC}^{7}$, verifica-se que não se contempla a questão da acessibilidade das TIC. O próximo item tratará desse conceito com detalhe.

Ao apontar a pertinência da utilização de software livre nas políticas de inclusão digital no Brasil, Silveira (2002) se refere à inclusão digital como "a universalização do acesso ao computador conectado à Internet, bem como ao domínio da linguagem básica para manuseá-lo com autonomia"(SILVEIRA, 2002, internet). Partindo disso, Silveira (2002) aponta que a dimensão do acesso e o escopo de um projeto de inclusão digital vai ser determinado pelos elementos e instrumentos a serem disponibilizados neste. Entre eles, o autor (2002) destaca o acesso: à rede de computadores; aos conteúdos da rede; à caixa postal eletrônica e a modos de armazenamento de informações; às linguagens básicas e instrumentos para usar a rede; às técnicas de produção de conteúdo; à construção de ferramentas e sistemas voltados às comunidades.

Este autor (2002) identifica três focos distintos e complementares entre si no que diz respeito às propostas de inclusão digital que têm sido feitas no Brasil: 1) cidadania, baseado no direito de interagir e de se comunicar na web; 2) combate à exclusão digital, voltada à profissionalização e à capacitação de camadas pauperizadas noções básicas de informática e 3) educação, visando à formação sóciocultural dos jovens para uma inserção autônoma na sociedade da informação. Silveira (2002) destaca que os projetos que reivindicam a ampliação da cidadania ganham cada vez mais força, desviando da questão da profissionalização que predominava num primeiro momento. No mesmo sentido, Valente (2005) salienta que mais do que acesso à informação e preparação para o mercado de trabalho, as TIC são um

7 Segundo o relatório-base 2006, disponível no site do CGI, entre as resoluções do Partnership on Measuring ICT for Development, iniciativa global que reuniu a União Internacional das Telecomunicações (UIT), a Organisation for Economic Co-operation and Development (OECD), a United Nations Conference on Trade and Development (UNCTAD), Organização das Nações Unidas par a Educação, a Ciência e a Cultura (UNESCO), a Organização das Nações Unidas (ONU) e a United Nations Information asd Communication Technologies Task force (UNICT Task Force) e o Banco Mundial, em junho de 2004, estava a de adotar um grupo de indicadores TIC comparáveis internacionalmente, a partir do qual se pudesse elaborar um banco de dados. $\mathrm{O}$ foco foi dado em três tipos de indicadores: infra-estrutura e acesso, domicílios e empresas. Em fevereiro de 2005, em uma Reunião Temática sobre Medição da Sociedade da Informação (WSIS), acordou-se os indicadores core para infraestrutura básica, domicílios, empresas e setor TIC. 
importante fator para dar voz para cada um e favorecer o diálogo no âmbito da inclusão digital.

Com o objetivo de categorizar os projetos de inclusão digital na cidade de Salvador, BA, Costa e Lemos (2005) desenvolveram uma matriz de análise a partir da qual se pode compreender a inclusão digital enquanto quatro tipos de capital:"o capital cultural é a memória de uma sociedade, o social, a potência política e identitária, o intelectual, a competência individual, e o técnico, a potência da ação e da comunicação" (LEMOS, 2004, internet).

A seguir, os autores (2005) propõem que se pode categorizar a inclusão digital enquanto três tipos de semânticas: técnica, econômica e cognitiva. De modo mais detalhado, trata-se do seguinte:

Nossa visão (e a matriz de análise de projetos de inclusão digital daí deriva) parte da premissa de que o processo de 'inclusão' deve ser visto sob os indicadores econômico (ter condições financeiras de acesso às novas tecnologias), cognitivo (estar dotado de uma visão crítica e de capacidade independente de uso e de apropriações dos novos meios digitais) e técnico (possuir conhecimentos operacionais de programas e de acesso à internet). (COSTA; LEMOS, 2005, internet).

Sob a ótica da inclusão digital de PNE, percebe-se que os três indicadores apontados devam ser levados em conta. No entanto, as semânticas cognitiva e técnica são as que merecem atenção em um primeiro momento, na medida em que a ausência de indicadores quanto à acessibilidade digital em plano nacional ou internacional, como demonstra a pesquisa sobre uso e posse de TIC consultada, pode ser o indicativo de um desconhecimento quanto à utilização das TIC pelos PNE e dos benefícios advindos dessa prática. O próximo item trata dessa relação. 


\subsection{Inclusão digital de Pessoas com Necessidades Especiais (PNE) ${ }^{8}$}

Os artigos pesquisados que relacionam a inclusão de PNE com TIC são provenientes de estudos da área de Educação. Em um deles, há inclusive um conceito de inclusão social voltado a PNE. Nele, Gil afirma que “inclusão social é o processo pelo qual a sociedade e as PNEs procuram adaptar-se mutuamente tendo em vista a equiparação de oportunidades e, conseqüentemente, uma sociedade para todos" (Gil apud SPIGAROLI; SANTOS; SCHLÜNZEN; et al., 2005, p. 212).

De maneira mais específica, para Warschauer (2006), as TIC podem ajudar portadores de deficiência física a superar problemas de mobilidade, limitações físicas ou discriminação social. Em outro contexto, este autor (2006) propõe que ainda que todas as tecnologias tenham influência sobre a estruturação das relações humanas, "o propósito real das TIC é reestruturar as comunicações e as relações humanas” (WARSCHAUER, 2006, p. 279). Este artigo aposta neste potencial de socialização através das TIC para a promoção do desenvolvimento sócio-cognitivo de PNE e, com isso, constituir-se em uma prática de inclusão digital. Se o uso do computador no ensino é capaz de favorecer o processo educacional, no caso de um PNE, este é um recurso que favorece a sua vida, segundo Schlünzen (2005), já que se trata de um meio de comunicação, de produção, de construção, de diagnóstico, entre outros.

O relato de pesquisa de Schlünzen (2005) aponta os benefícios da utilização de computadores no ensino de PNE de tipo física. Em resumo, os resultados obtidos foram:

O computador no desenvolvimento de projetos pôde potencializar a comunicação, a criação e a produção dos alunos, sendo também usado como instrumento de diagnóstico e de avaliação formativa, uma vez que permitia verificar a capacidade intelectual da criança com necessidades especiais físicas. Além disso, por meio da

\footnotetext{
${ }^{8}$ São PNE todas as pessoas que em maior ou menor medida precisam de algum apoio ou suporte externo para se desenvolver e serem autônomas. Consideramos que necessidades especiais engloba um conjunto de aspectos que ultrapassam em muito, o antigo conceito de "deficiente". Por esse motivo, podemos considerar dentro do espectro de necessidades especiais grupos sociais como terceira idade, desempregados, pessoas carentes, além das pessoas com deficiências motoras, cognitivas e/ou sociais. Essa mudança de enfoque da "deficiência" para a necessidade especial, leva consigo a concepção da variabilidade do caráter permanente da deficiência para o transitório, isto é, da visão de "adaptar a pessoa deficiente" para viver na sociedade à da "inclusão" pela "adaptação da sociedade" e pela superação das necessidades. (Passerino, 2003).
} 
formalização, da representação, da execução e da depuração de suas idéias (Valente, 1993), os próprios alunos descobriram e corrigiram seus erros com maior facilidade, depurando e refletindo sobre todo o seu processo de construção do conhecimento. Com o computador, o educando conseguiu realizar tarefas de maneira independente, sem o auxílio de outras pessoas, superando ou minimizando as barreiras com o mundo sem que o seu comprometimento se evidenciasse. (SCHLÜNZEN, 2005, p. 205-206).

Nossa abordagem privilegia o papel de socialização das TIC para as PNE. De acordo com esta perspectiva, o desenvolvimento cultural de uma criança vincula-se em um primeiro momento de um plano social (coletivo) e, após, em um plano psicológico (individual) (VYGOTSKY, 1988). Frente a isso, Passerino (2005) afirma que a utilização das TIC no processo educativo pode promover o desenvolvimento social, afetivo e cognitivo de todos os sujeitos, particularmente dos PNE que se beneficiam do uso das TIC, pois estas propiciam "espaços alternativos" de comunicação e construção, não somente individual, mas também colaborativo.

Outro estudo evidencia este aspecto. Em As Tecnologias de Informação $e$ Comunicação como ferramentas potencializadoras para a inclusão: um desafio para a sociedade (2005), os autores falam sobre os resultados de uma experiência no Ambiente Potencializador para Inclusão (API) ${ }^{9}$ em 2001 e 2002. Entre os projetos desenvolvidos nesse Ambiente, destaca-se o Projeto Internet. Constatando a utilização crescente da internet no processo de ensino-aprendizagem, os autores utilizaram-na no API "dando a cada aluno a autonomia para criar sua rádio virtual, homepage e comunicar-se com pessoas próximas e distantes, por meio de ferramentas que expressassem seus interesses e que tivessem significado dentro de seu contexto social" (SPIGAROLI, SANTOS, SCHLÜNZEN, et al., 2005, p. 222). A escolha da música nas rádios e dos temas a serem tratados na homepage motivaram os alunos, favorecendo sua autonomia. Já a utilização de chats, e-mail e pesquisa na internet propiciou a busca por contatos em outros sites, trocas de mensagens, etc., atividade através das quais estabeleceram contato com pessoas que até então não conheciam.

\footnotetext{
9 Idealizado como um trabalho de pesquisa realizado por Portela (2001), aluna do Curso de Pedagogia da Faculdade de Ciências e Tecnologia (FCT) da Universidade Estadual Paulista Júlio de Mesquita Filho (Unesp) de Presidente Prudente, com apoio da Fapesp. Em 2002, o projeto foi continuado, com 9 estagiárias, orientadas pela Prof. Dra. Elisa Tomoe Moriya Schlünzen, tendo atendido 13 alunos PNE.
} 
Propostas educacionais que utilizaram a internet confirmaram esta premissa, atestando que é pertinente incentivar a socialização para ampliar a autonomia de PNE (SANTAROSA, 200o) (PASSERINO; SANTAROSA, 2003) (TIJIBOY; SANTAROSA, 2000). No entanto, questiona-se até que ponto os portais na $w e b$, as ferramentas de publicação de blogs ou plataformas de redes sociais na web estão atentos a essa parcela da população. E, por outro lado, quais são as necessidades sentidas por este público ao utilizarem esses recursos que tanto podem contribuir para sua formação social, cultural, cidadã. Na medida em que se pretende investigar a inclusão digital de PNE via socialização on-line, percebe-se a interface dessa questão com a da acessibilidade digital. O próximo item trata desse ponto.

\section{Acessibilidade digital}

O conceito de acessibilidade surge ligado a questões físicas relativas a facilidades de acesso (barreira arquitetônicas) e à reabilitação física e profissional, sendo que, posteriormente, é transferido para a informática na questão de acesso à $w e b$ especificamente. Assim, entre as décadas de 1940 e 1960, o termo tem uma aplicação direta com questões físicas e funcionais. Mas é a partir da década de 1980, impulsionado pelo Ano Internacional das Pessoas Deficientes (1981), que a questão da acessibilidade e eliminação de barreiras arquitetônicas ganha destaque internacional e transforma-se em metas para todos os países desenvolvidos e em vias de desenvolvimento. Nesse período, surge também o conceito de Design Universal na concepção de um design adaptável às diversas necessidades da população.

Na década de 1990, com a popularização da Internet e de comunidades virtuais nos EUA, percebe-se a necessidade de prover esse mesmo acesso universal na web com a construção de ambientes virtuais acessíveis. Neste sentido, dois consórcios mundiais, o W3C (Consórcio para a Web) e a WAI (Iniciativa para a Acessibilidade na Rede) são os principais responsáveis pela popularização do termo a partir de fins dos anos 1990, quando a Internet, em especial a web, tornou-se mais expressiva, ao estabelecerem os padrões e protocolos que sistemas computacionais deveriam seguir para serem considerados acessíveis.

Em termos legais, o conceito de acessibilidade surge no Brasil já fazendo referência também aos meios de comunicação. Assim, em 1999, o Decreto Lei no 
3.298 definiu a acessibilidade na Administração Pública Federal como "possibilidade e condição de alcance para utilização com segurança e autonomia dos espaços, mobiliário e equipamentos urbanos das instalações e equipamentos esportivos, das edificações, dos transportes e dos sistemas e meios de comunicação” (BRASIL, 1999).

De acordo com o site Acessibilidade Brasil ${ }^{10}$, acessibilidade "representa para o nosso usuário não só o direito de acessar a rede de informações, mas também o direito de eliminação de barreiras arquitetônicas, de disponibilidade de comunicação, de acesso físico, de equipamentos e programas adequados, de conteúdo e apresentação da informação em formatos alternativos" (Acessibilidade Brasil, 2006, internet).

Em função dessa especificidade, propõe-se o termo acessibilidade digital como fator de diferenciação conceitual da acessibilidade arquitetônica e urbanística, denominada física, e considera-se a acessibilidade universal o construto teórico que engloba todas as concepções relacionadas com a acessibilidade, incluindo aí a questão do governo eletrônico que representa uma forma nova de acesso aos processos públicos e políticos da cidadania que ainda encontra-se em consolidação.

Para Granollers (2004), acessibilidade (digital) significa proporcionar flexibilidade para adaptação às necessidades de cada usuário e a suas preferências e/ou limitações. Conforto e Santarosa (2002) consideram a acessibilidade (à web)

[...] como sinônimo de aproximação, um meio de disponibilizar a cada indivíduo interfaces que respeitem suas necessidades e preferências [...]. Muitas vezes as discussões sobre acessibilidade ficam reduzidas às limitações físicas ou sensoriais dos sujeitos com necessidade especiais, mas esses aspectos podem trazer benefícios a um número bem maior de usuários, permitindo que os conhecimentos disponibilizados na Web possam estar acessíveis a uma audiência muito maior, sem com isso, prejudicar suas características gráficas ou funcionais. (CONFORTO; SANTAROSA, 2002, p. 92-94).

É importante destacar que a acessibilidade digital só pode ser proporcionada através de uma combinação entre hardware e software, que oferecem, respectivamente, os mecanismos físicos para superar barreiras de percepção, e acesso a funções e informações.

${ }^{10}$ Disponível em http://www.acessobrasil.com.br 
Por vezes, os conceitos de acessibilidade e usabilidade se confundem. Enquanto a usabilidade volta-se mais para as expectativas e para a capacidade do usuário em entender e perceber as estratégias de utilização do software, a acessibilidade está voltada para as condições de uso, como o usuário se apresenta frente às interfaces interativas, como essa troca deve acontecer, e, principalmente, como se dará o acesso do usuário às informações disponíveis.

Ser acessível é permitir o uso. Apesar da obviedade, muitas vezes ocorre a interpretação indevida de que estar visível e ser perceptível dá a uma interface a condição de ser acessível, mas considerando as necessidades especiais de cada sujeito, atender a esse requisito não dá essa condição assistiva. De acordo com Dias (2003), a acessibilidade mede-se em termos de flexibilidade do produto para atender às necessidades e preferências do maior número de pessoas. Mas isso não é suficiente, ele também deve ser compatível com tecnologias assistivas ao viabilizar sua própria adaptabilidade de acordo com as necessidades e demandas dos usuários, independente do grau, nível ou intensidade de sua necessidade, destaca Dias (2003).

De acordo com Granollers (2004), embora todos concebam como necessário atender aos critérios de acessibilidade definidos pela $\mathrm{W}_{3} \mathrm{C}^{11}$, "ninguém coloca em prática”. Como exemplo, podemos citar a Microsoft, IBM, Sun, Apple, entre outras que incluem algum tipo de acessibilidade nos seus sistemas operacionais e explicam detalhadamente nos seus sites as vantagens de seus recursos e ferramentas. Porém, em seus próprios sistemas, na hierarquia de acesso a esses recursos, estas ferramentas estão localizadas em níveis inferiores sendo necessário o usuário "navegar por vários níveis" até poder habilitar o recurso. Isso mostra que do ponto de vista político, são consideradas opções para uma minoria.

Acreditamos que é possível através das TIC promover a Inclusão Digital de PNE através de três grandes áreas: 1)tecnologias assistivas ${ }^{12}$ : acesso ao computador

\footnotetext{
${ }_{11}$ W3C: http://www.w3.org Site do World Wide Web Consortium. O W3C é um organismo internacional fundado em 1994, sem vínculos externos, cuja missão é auxiliar a Web a atingir seu pleno potencial, desenvolvendo tecnologias, recomendações e software que promovam sua evolução e garantam sua interoperabilidade.

12 O termo "tecnologia assistiva" designa os equipamentos (hardware) e os programas (software) que têm como função mediar a interação homem-computador, possibilitando às PNE a realização de atividades motoras, perceptivas e cognitivas. Adotamos definição semelhante à de "interface homem-computador" de Lévy (1993, p. 176): “(...) conjunto de
} 
através de dispositivos de hardware e software; 2) acesso ao software através do “desenho universal”. O software acessível é concebido e desenvolvido para o maior número possível de pessoas, incluindo as PNE; 3) acesso à Internet (conteúdos e software para web) por PNE. Caracteriza-se pela flexibilidade da informação e interação relativamente ao respectivo suporte de apresentação. Esta flexibilidade permite a sua compreensão e utilização por pessoas com necessidades especiais, bem como a utilização em diferentes ambientes e situações e através de diversos equipamentos e navegadores.

\section{Considerações Finais}

Entende-se que a acessibilidade e inclusão digital não dizem respeito apenas ao acesso à rede de informações, mas também à eliminação de barreiras de comunicação, equipamentos e software adequados às diferentes necessidades especiais, bem como conteúdo e apresentação da informação em formatos alternativos e contextualizados também com as necessidades da comunidade onde este sujeito está inserido, ou seja, garantia de mobilidade, usabilidade de recursos computacionais para PNE. Assim, a questão da acessibilidade está intimamente relacionada com a inclusão, pois, somente a partir de espaços acessíveis é que poderemos realmente incluir os indivíduos. (PASQUALOTTI; PASSERINO, 2006).

Por outro lado, quando se considera a Inclusão Digital como um processo para a Inclusão Social, não se pretende referir meramente à utilização e manuseio de computadores e da Internet pelas pessoas. Considera-se que tal uso, embora necessário, esgota-se em si mesmo quando não é voltado a apoiar o desenvolvimento sócio-cognitivo do sujeito (Passerino e Santarosa, 2002, 2003) de forma a garantir a acessibilidade universal.

Por este motivo, faz-se necessário trabalhar na busca de soluções efetivas para que pessoas com necessidades especiais ou não tenham amplo acesso às TIC, já que as TIC atuam como ferramentas de inclusão na medida que permitem a

programas e aparelhos materiais que permitem a comunicação entre um sistema informático e seus usuários humanos", que abrangem os equipamentos de entrada e saída de dados (síntese de voz, software de reconhecimento de voz, braile), auxílios alternativos de acesso (ponteiras de cabeça, de luz), teclados adaptados ou alternativos, chaves, acionadores, sistemas de comunicação alternativa e aumentativa, etc., que permitem às pessoas com necessidades especiais, usarem o computador. 
participação dos indivíduos na sociedade por outras vias de acesso além das tradicionalmente estabelecidas.

Para tanto, é necessário a formulação de políticas públicas de orientação, educação formal e não-formal, proficiência tecnológica e de uso das tecnologias da informação e comunicação e das tecnologias assistivas, pois esses recursos podem servir de suporte a inúmeras atividades para todas as pessoas.

A popularização do uso e das ferramentas de socialização on-line pode ser uma frente de ação nesse sentido. Na medida em que se constata que a socialização é fundamental no desenvolvimento cultural de um PNE, percebe-se que as TIC podem ser utilizadas para tanto. O levantamento do uso que PNE fazem de ferramentas da Web 2.0 ${ }^{13}$, bem como a avaliação de seu potencial inclusivo quanto à acessibilidade, a ser mensurado a partir dos critérios de acessibilidade disponíveis no site Acessibilidade Brasil, serão os próximos passos dessa pesquisa. A ausência de indicadores quanto ao acesso de PNE às TIC pode dificultar a implementação de medidas de acessibilidade digital, ainda que reforce a importância desta investigação.

\section{Referências}

ACESSIBILIDADE BRASIL. O que é acessibilidade. Disponível em http://www.acessobrasil.org.br Acesso em 4 dez. 2006.

AZEVEDO, P. H.; BARROS, J. F. O nível de participação do Estado na gestão do esporte brasileiro como fator de inclusão social de pessoas portadoras de deficiência. Revista Brasileira de Ci e Movimento. Brasília, v. 12 n. 1 p. 77-84. Jan/Mar 2004.

BRASIL. Presidência da República. Casa. Decreto Lei 3.298 Disponível em https://www.planalto.gov.br/ccivil/decreto/d3298.htm. Acesso em $4 \mathrm{dez}$. 2006.

CONFORTO, D. e SANTAROSA, L. M. C. Acessibilidade à Web : Internet para Todos. Revista de Informática na Educação: Teoria, Prática - PGIE/UFRGS v. $5 \mathrm{n}^{0} 2,2002$.

\footnotetext{
${ }^{13}$ Segundo O `Reilly (2005, internet), Web 2.0 é uma denominação para uma segunda geração de serviços para internet que visa ampliar as formas de participação dos usuários na produção de compartilhamento de informações on-line. $\mathrm{O}$ termo Web 2.0 foi popularizado pela O`Reilly Media e pela Media Live International como denominação de uma série de conferências realizadas a partir de 2004. Compreende ferramentas gratuitas de produção e compartilhamento de informações em vários formatos (texto, som, animação, fotos, etc.), além de permitir a interação entre os usuários, como blogs, podcast, Flickr e Wikipedia.
} 
COSTA, L.; LEMOS, A. Um modelo de inclusão digital: o caso da cidade de Salvador. In: Revista de Economia Política de las Tecnologias de la Informatión e Comunicación. Vol. VIII, n. 6, sep.-dic. 2005. Disponível em http://www.eptic.com.br. Acesso em 4 dez. 2006.

DIAS, C. Usabilidade na WEB. Criando portais mais acessíveis. Rio de Janeiro: Alta Books, 2003.

DUPAS, G. Economia e Exclusão Social: Pobreza, Emprego, Estado e o Futuro do Capitalismo. São Paulo: Paz e Terra, 2000.

GRANOLLLERS, T. MPI+u Uma metodologia que integra la ingenieria del software, la interacción persona-ordenador y la accesibilidad en el contexto de equipos de desarrollo multidisciplinares. Tesis de doctorado. Universidad de Lleida, julio 2004.

LADEIRA, F.; AMARAL, I. A educação de alunos com multideficiência nas Escolas de Ensino Regular. Coleção Apoios Educativos. Lisboa: Ministério da Educação.Departamento da Educação Básica, 1999.

LEMOS, A. Cibercidades: um modelo de inteligência coletiva. In: LEMOS, A. (org.). Cibercidade: a cidade na cibercultura. Rio de Janeiro: E-paper, 2004. pp. 19-26.

OLIVEIRA, C. B. Mídia, cultura corporal e inclusão: conteúdos da educação física escolar. Revista Digital - Buenos Aires - Año 10 No. 77 - Octubre, 2004. Disponível em: http://www.efdeportes.com . Acesso em 4 dez. 2006.

OLIVEIRA, J. A. B.; et al. As Tecnologias de Informação e Comunicação como ferramentas potencializadoras para a inclusão: um desafio para a sociedade. In: PELLANDA, N. M. C.; SCHLÜNZEN, E. T. M.; SCHLÜNZEN Jr. , K. Inclusão digital: tecendo redes afetivas/cognitivas. Rio de Janeiro: DP\&A, 2005. pp. 211-231.

O'REILLY, Tim. What is Web 2.o - Design Patterns and Business for the Next Generation of Software, 2005. Disponível em http:// www.oreillynet.com. Acesso em 16 de setembro de 2006.

PASSERINO, L. Pessoas com autismo em ambientes digitais de aprendizagem : estudo dos processos de interação social e mediação. Tese de Doutorado. Universidade Federal do Rio Grande do Sul. Programa de Pós-Graduação em Informática na Educação 2005.

PASSERINO, L. e SANTAROSA L.M C. (2002). REDESPECIAL-BRASIL e Universidade Luterana do Brasil, um relato de experiência. Anais. III Congresso Iberoamericano de Informática na Educação Especial 2002 CIEE2002. Fortaleza.

. (2003) Inclusão Digital de Pessoas com necessidades educacionais especiais: EDUKITO. $8^{\circ}$ Taller Internacional de Software Educativo TISE 2003. Santiago do Chile, Chile 24-26 de novembro.

PASQUALOTTI, P.; PASSERINO, L. Critérios de Usabilidade e de Acessibilidade em software de construção de narrativas colaborativas. IN: Anais do IBERDISCAP, 2006, Vitória, ES, 20-22 de Fev. de 2006. 
SANTAROSA, L. INCLUSÃO DIGITAL: espaço possível para pessoas com necessidade educacionais especiais. In: Cadernos de Educação Especial, cidaden $^{\circ}$ 20, 2002.

SILVEIRA, S. A. Inclusão digital, sofware livre e globalização contrahegemônica. Disponível em http://www.softwarelivre.gov.br/softwarelivre/artigos/artigo 02. Acesso em 4 dec. 2006.

SCHLÜNZEN, E. T. M. A tecnologia como inclusão de Pessoas com Necessidades Especiais (PNE). In: PELLANDA, N. et al. Inclusão digital: tecendo redes afetivas/cognitivas. Rio de Janeiro: DP\&A, 2005. pp. 195-210.

SPOSATI, A.A fluidez da inclusão/exclusão social. Ciência e Cultura, vol. 58, no. 4., São Paulo, Out/Dec. 2006.

. Mapa da Exclusão/Inclusão da Cidade de São Paulo. São Paulo: PUCSP, 1996.

VYGOTSKY, L. S Formação Social da Mente. 6th Edition.- São Paulo: Martins Fontes, 1988.

WARSCHAUER, Mark. Tecnologia e Inclusão Social. A exclusão digital em debate.

São Paulo: Senac, 2006. 